\title{
Adubação nitrogenada e características agronômicas em amoreira-preta
}

\author{
Ivan dos Santos Pereira(1), Luciano Picolotto(1), Rafael da Silva Messias ${ }^{(1)}$, Mariana da Luz Potes ${ }^{(1)}$ \\ e Luis Eduardo Correa Antunes ${ }^{(1)}$
} (1)Embrapa Clima Temperado, BR-392, Km 78, Caixa Postal 403, CEP 96010-971 Pelotas, RS. E-mail: ivanspereira@gmail.com,
picolotto@gmail.com, rafael.embrapa@yahoo.com.br, marianapotes@yahoo.com.br, luis.antunes@embrapa.br

Resumo - O objetivo deste trabalho foi avaliar a influência de doses crescentes de nitrogênio sobre o crescimento vegetativo, a produção e os níveis foliares de nutrientes da amoreira-preta (Rubus spp.). O experimento foi realizado com as cultivares Tupy e Xavante, na região sul do Rio Grande do Sul, de 2008 a 2012. Os tratamentos consistiram da aplicação de cinco doses de $\mathrm{N}(0,0,7,5,15,0,22,5$ e 30,0 g por planta), aplicados na adubação de manutenção, após a implantação da lavoura. Utilizou-se o delineamento de blocos ao acaso, com quatro repetições. Foram avaliadas as variáveis: densidade de hastes, massa de matéria seca de poda, índice de clorofila, produção por planta, número de frutos e composição nutricional das folhas $(\mathrm{N}, \mathrm{K}$, $\mathrm{Ca}, \mathrm{Mg}$ e S). A adubação nitrogenada influenciou significativamente o crescimento vegetativo, a produção e a composição nutricional das folhas. As cultivares apresentaram resposta distinta à aplicação de N, em que 'Tupy' foi mais exigente que 'Xavante'. As doses de $\mathrm{N}$ atualmente recomendadas para a cultura da amoreira-preta são satisfatórias para a máxima produção de 'Xavante', mas insuficientes para 'Tupy'.

Termos para indexação: Rubus, crescimento vegetativo, nitrogênio, nutrição mineral, pequenas frutas, produção.

\section{Nitrogen fertilization and agronomic characteristics in blackberry}

\begin{abstract}
The objective of this work was to evaluate the influence of increasing doses of nitrogen on vegetative growth, yield and leaf nutrient levels of blackberry (Rubus spp.). The experiment was carried out with the cultivars Tupy and Xavante, in southern state of Rio Grande do Sul, Brazil, from 2008 to 2012. It was used a randomized block design, with four replicates. Treatments consisted of five $\mathrm{N}$ doses $(0.0,7.5,15.0,22.5$ and 30.0 g per plant), applied as maintenance fertilization after the crop establishment. The following variables were evaluated: cane density, pruned dry mass, chlorophyll index, yield, number of fruit, and nutritional composition of leaves for $\mathrm{N}, \mathrm{K}, \mathrm{Ca}, \mathrm{Mg}$ and $\mathrm{S}$. The fertilization treatments significantly influenced the vegetative growth, yield, and nutrient composition of leaves. The cultivars responded differently to nitrogen application, with 'Tupy' being more demanding than 'Xavante'. The currently recommended nitrogen rate for blackberry cultivation is suitable for maximum yield of 'Xavante', but it is not sufficient for 'Tupy'.
\end{abstract}

Index terms: Rubus, vegetative growth, nitrogen, mineral nutrition, small fruits, yield.

\section{Introdução}

O mercado de pequenas frutas no Brasil tem aumentado nos últimos anos (Fachinello et al., 2011). Entretanto, no caso da amoreira-preta (Rubus spp. Rosaceae), para que haja incrementos na produção de modo a atender à demanda crescente, ainda são necessárias pesquisas sobre sistemas de produção, condições edafoclimáticas (Antunes et al., 2010; Campagnolo \& Pio, 2012; Ilha, 2012) e, principalmente, sobre nutrição mineral (Castaño et al., 2008; Strik \& Finn, 2012).

Um dos fatores de produção mais intensivamente utilizados na busca pela máxima eficiência agronômica é a adubação mineral solúvel, uma vez que a resposta da planta à aplicação é rápida e, na maioria das vezes, intensa. Ensaios de adubação têm sido conduzidos para determinar a dose ótima de nitrogênio em amoreiras e outras pequenas frutas (Jara-Peña et al., 2002; Quezada et al., 2007; Buskiene \& Uselis, 2008; Kowalenko et al., 2008; Bryla et al., 2012; Banãdos et al., 2012). Esses ensaios, no entanto, têm apresentado resultados variáveis, em razão de diferenças na fertilidade do solo, idade das plantas e exigência das cultivares (Castaño et al., 2008; Strik, 2008; Strik \& Finn, 2012).

$\mathrm{O} \mathrm{N}$ é o elemento que a amoreira-preta necessita em maior quantidade e o principal responsável pelo crescimento, desenvolvimento e produção das plantas 
(Naraguma \& Clark, 1998; Mohadjer et al., 2001; Strik, 2008). O conteúdo ótimo necessário para o crescimento da cultura está entre 2 e $5 \%$ da matéria seca das plantas (Castaño et al., 2008). Quando aplicado em manutenção, o $\mathrm{N}$ é alocado principalmente para o crescimento de novas hastes, folhas e frutos, enquanto o $\mathrm{N}$ já acumulado e armazenado nos tecidos da planta permanece nestes até o final da estação de crescimento (Naraguma et al., 1999; Strik, 2008).

A deficiência de $\mathrm{N}$ surge primeiro em folhas mais velhas e é caracterizada pelo amarelecimento do limbo foliar, pecíolos avermelhados ou rosados, crescimento nulo das hastes - que passam a apresentar coloração vermelha ou púrpura -, além do baixo crescimento da planta (Castaño et al., 2008).

As doses de $\mathrm{N}$ recomendadas na literatura variam muito, principalmente em razão de diferenças entre as cultivares. No primeiro ano, recomenda-se a aplicação de 34 a $56 \mathrm{~kg} \mathrm{ha}^{-1}$, independentemente do hábito de crescimento da cultivar; a partir do segundo ano, de 56 a $78 \mathrm{~kg} \mathrm{ha}^{-1}$, para cultivares rasteiras, e de 56 a $90 \mathrm{~kg} \mathrm{ha}^{-1}$ para cultivares de hábito ereto (Alleyne \& Clark, 1997; Strik, 2008). A única indicação de adubação existente para amoreira-preta no Brasil não leva em consideração a cultivar, e recomenda doses de 0 a $100 \mathrm{~kg} \mathrm{ha}^{-1}$ de N (15 g por planta, em espaçamento 0,5x3,0 m), em adubação de manutenção (Manual de adubação e calagem para os estados do Rio Grade Sul e Santa Catarina, 2004).

O objetivo deste trabalho foi avaliar a influência de doses crescentes de nitrogênio sobre o crescimento vegetativo, a produção e os níveis foliares de nutrientes de amoreira-preta, na região sul do Rio Grande do Sul.

\section{Material e Métodos}

O experimento foi realizado em campo, em área experimental da Embrapa Clima Temperado, Pelotas,

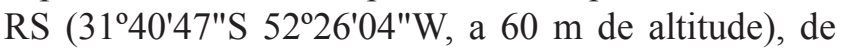
setembro de 2008 (implantação) a maio de 2012 (última avaliação). O clima da região, segundo a classificação de Köppen, é do tipo Cfa, temperado e úmido, com verões quentes. O solo da área experimental foi classificado como Argissolo Vermelho-Amarelo distrófico (Santos et al., 2006), com as seguintes características químicas: $\mathrm{pH} \mathrm{H} \mathrm{H}_{2} \mathrm{O}, 5$,9; SMP, 6,5; MO, $11 \mathrm{~g} \mathrm{~kg}^{-1}$; P, $24 \mathrm{mg} \mathrm{dm}^{-3}$; $\mathrm{K}, 58 \mathrm{mg} \mathrm{dm}{ }^{-3} ; \mathrm{Ca}, 1,8 \mathrm{cmol}_{\mathrm{c}} \mathrm{dm}^{-3} ; \mathrm{Mg}, 1,0 \mathrm{cmol}_{\mathrm{c}} \mathrm{dm}^{-3}$; $\mathrm{Na}, 6,0 \mathrm{mg} \mathrm{dm}^{-3}$; B, 0,2 $\mathrm{mg} \mathrm{dm}^{-3} ; \mathrm{Cu}, 0,6 \mathrm{mg} \mathrm{dm}^{-3}$; $\mathrm{Fe}, 0,4 \mathrm{~g} \mathrm{dm}^{-3}$; Mn, 2, $1 \mathrm{mg} \mathrm{dm}{ }^{-3} ; \mathrm{Zn}, 0,6 \mathrm{mg} \mathrm{dm}^{-3}$.
Utilizaram-se as cultivares de amoreira-preta Tupy e Xavante, em espaçamento $0,5 \times 3,0 \mathrm{~m}$ (6.667 plantas por hectare). As plantas foram conduzidas sem sustentação e mantidas eretas por meio do manejo da poda.

Os tratamentos de adubação consistiram de cinco doses de $\mathrm{N}(0,0,7,5,15,0,22,5$ e 30,0 g por planta), aplicadas na adubação de manutenção, nos anos posteriores ao de implantação da lavoura. As doses, 0,0 , $7,5,15,0,22,5$ e 30,0 g correspondem a $0,50,100,150$ e $200 \%$ da dose recomendada (Manual de adubação e calagem para os estados do Rio Grande do Sul e Santa Catarina, 2004). As doses de $\mathrm{P}$ e K não variaram entre os tratamentos, e foram estimadas conforme a interpretação dos resultados da análise de solo para a cultura (Manual de adubação e calagem para os estados do Rio Grande do Sul e Santa Catarina, 2004).

As doses de $\mathrm{N}$ em manutenção foram parceladas em três aplicações. Nas safras 2009/2010, 2010/2011 e 2011/2012, a primeira aplicação foi realizada no início da brotação, nos dias 26/8/2009, 9/9/2010 e 22/9/2011, respectivamente. A segunda e terceira aplicações foram realizadas aos 15 e 30 dias após a primeira. As adubações fosfatadas e potássicas de manutenção foram realizadas em aplicação única, no início da brotação. As fontes utilizadas para a adubação nitrogenada, fosfatada e potássica foram, respectivamente, sulfato de amônio, superfosfato triplo e cloreto de potássio. O sulfato de amônio foi utilizado por também apresentar enxofre em sua composição. A aplicação foi feita em superfície, sem incorporação, em um raio de $25 \mathrm{~cm}$ ao redor das plantas.

As variáveis avaliadas foram: densidade de hastes (hastes $\mathrm{m}^{-1}$ ), obtida pela contagem do número de hastes por metro na linha de cultivo; massa de matéria seca de poda (g por planta), retirada no outono de 2012; índice de clorofila, estimado com auxílio de um ClorofiLOG (Falker Automação Agrícola Ltda., Porto Alegre, RS); produção por planta (g por planta), obtida pela soma da massa total de frutos colhidos nas safras 2009/2010, 2010/2011 e 2011/2012; número de frutos, contagem do número total de frutos colhidos em cada planta, na safra 2010/2011; e análise nutricional das folhas, realizada quanto aos macronutrientes $\mathrm{N}, \mathrm{K}, \mathrm{Ca}, \mathrm{Mg}$ e S, nas safras 2009/2010, 2010/2011 e 2011/2012.

$\mathrm{O}$ experimento foi implantado em delineamento experimental de blocos ao acaso, com quatro repetições, em que cada unidade experimental foi constituída de cinco plantas, tendo sido avaliadas as três centrais. Os resultados foram submetidos à análise de variância, 
em que variáveis com diferenças significativas, para fatores qualitativos, foram comparadas pelo teste de Tukey, a $5 \%$ de probabilidade. As variáveis com diferenças significativas para o fator quantitativo foram submetidas à análise de regressão. As análises foram realizadas com uso do programa estatístico WinStat, versão 2.1 (Machado \& Conceição, 2003).

\section{Resultados e Discussão}

As doses de $\mathrm{N}$ em adubação de manutenção influenciaram significativamente $\mathrm{o}$ crescimento vegetativo, a produção e os níveis de nutrientes na folha das cultivares avaliadas (Figuras 1 e 2).
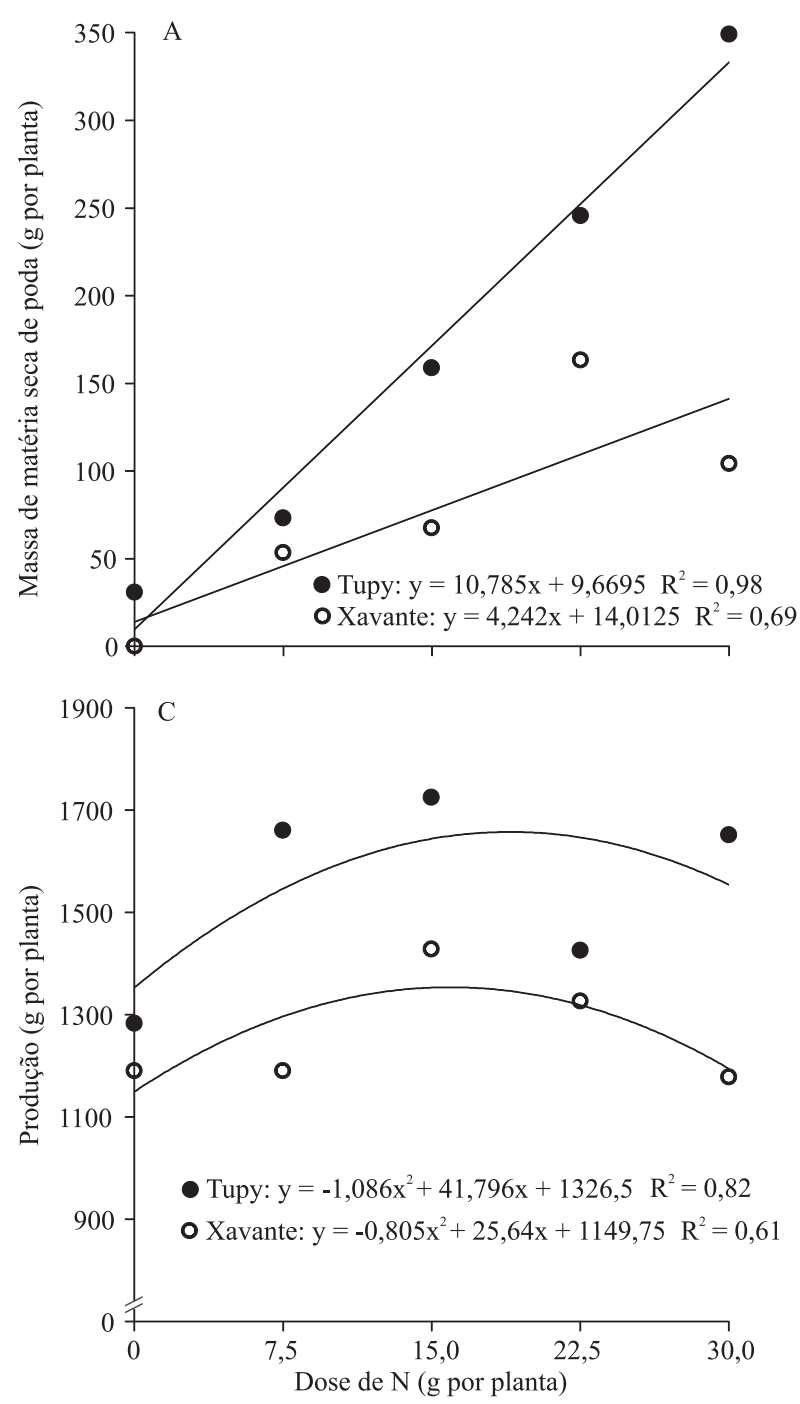

A massa de matéria seca de poda e o índice de clorofila aumentaram linearmente, em resposta às doses de N (Figura 1). Este resultado é condizente com a importância decisiva, atribuída ao nutriente, para o crescimento vegetativo de amoreira-preta (Castaño et al., 2008; Strik, 2008; Strik \& Finn, 2012). Quanto à variável massa de matéria seca de poda, 'Tupy' foi mais responsiva à adubação nitrogenada. Diferentes níveis de resposta à adubação, em cultivares de amoreira-preta, estão associadas ao grupo ao qual elas pertencem. Esses grupos, em termos gerais, estão relacionados ao hábito de crescimento (Strik, 2008). No presente experimento, além de terem hábitos de crescimento distintos, as cultivares diferem também
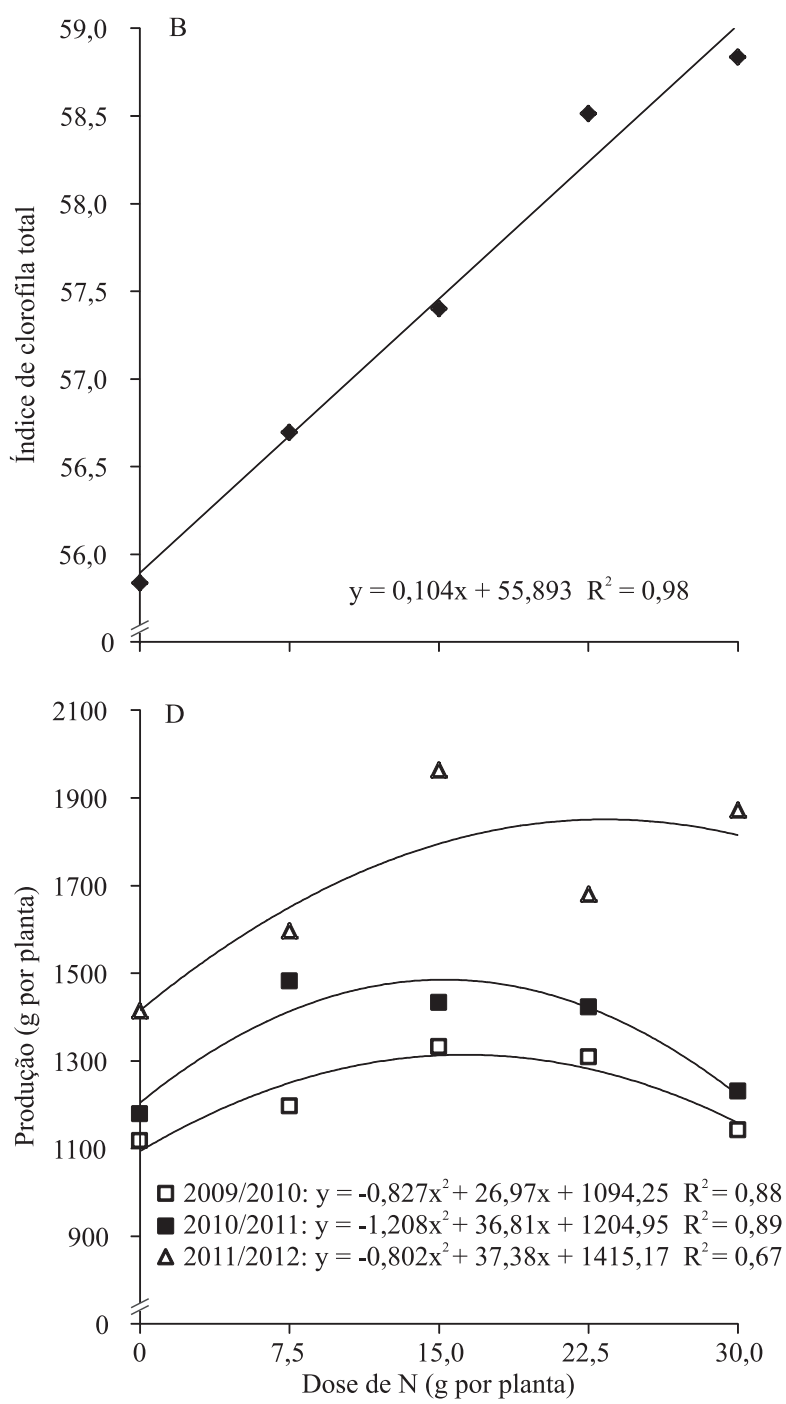

Figura 1. Resposta das cultivares de amoreira-preta Tupy e Xavante à adubação nitrogenada, em diferentes safras: A, massa de matéria seca de poda; B, índice de clorofila total; e C e D, produção por planta. 

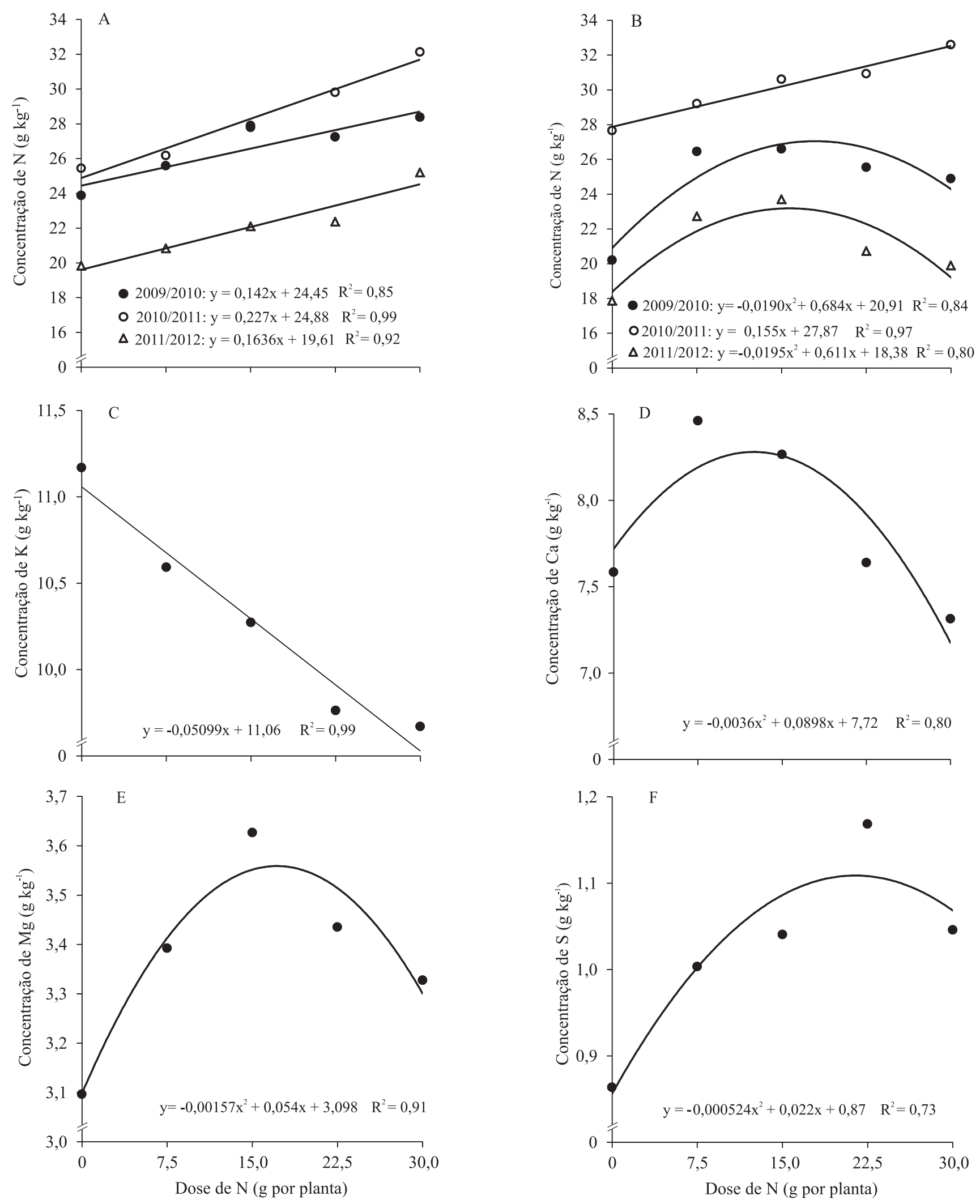

Figura 2. Concentrações foliares de nutrientes em resposta à adubação nitrogenada: A, nitrogênio na cultivar Tupy; B, nitrogênio na cultivar Xavante; C, potássio; D, cálcio; E, magnésio; e F, enxofre. 
quanto à presença de espinhos. Pereira (2008) observou uma ordem de exportação de nutrientes distinta para 'Tupy' e 'Xavante', que indica exigência nutricional distinta entre elas.

$\mathrm{O}$ índice de clorofila aumentou significativamente com o aumento das doses de $\mathrm{N}$ e correlacionou-se $(\mathrm{r}=0,88, \mathrm{p}<0,04)$ com os teores foliares de $\mathrm{N}$ (Figura 2). Este resultado indica a possibilidade de a diagnose nutricional de $\mathrm{N}$ na amoreira-preta ser realizada por meio de metodologias não destrutivas, como a medida do índice de clorofila.

Ao contrário dos demais parâmetros de crescimento estudados, a densidade de hastes não respondeu significativamente às doses de $\mathrm{N}$, o que difere dos resultados obtidos por Naraguma \& Clark (1998), que verificaram efeito positivo da adubação nitrogenada sobre o número de hastes. Castaño et al. (2008), no entanto, relatam que deficiências nutricionais podem induzir a formação de novas hastes.

As cultivares não diferiram quanto ao índice de clorofila; porém, 'Tupy' apresentou maior massa de matéria seca de poda, e 'Xavante' maior densidade de hastes (Tabela 1). Quanto à produção de frutos, houve interação entre doses e cultivares e, também, entre doses e safras (Figura 1). A produtividade da cultivar Tupy foi mais sensível à adubação nitrogenada, tendo passado de $1.283 \mathrm{~g}$ por planta, no tratamento sem adubação, para $1.728 \mathrm{~g}$ (incremento de $35 \%$ ), com a aplicação 19,24 g de N por planta, dose de máxima eficiência técnica. Na cultivar Xavante, a produção por planta passou de $1.191 \mathrm{~g}$ para $1.354 \mathrm{~g}$ (incremento de $14 \%$,) com a dose estimada de $15,93 \mathrm{~g}$ de $\mathrm{N}$ por planta. Diferenças na exigência nutricional de diferentes cultivares de amoreira-preta têm sido relatadas (Pereira, 2008; Strik, 2008).

Tabela 1. Massa de matéria seca de poda (MSP), densidade de hastes, índice de clorofila total, produção (g por planta) e número de frutos por planta, das cultivares Tupy e Xavante de amoreira-preta, e nas safras 2009/10, 2010/11 e 2011/12 ${ }^{(1)}$.

\begin{tabular}{lccccc}
\hline $\begin{array}{l}\text { Cultivar/ } \\
\text { safra }\end{array}$ & $\begin{array}{c}\text { MSP (g por } \\
\text { planta) }\end{array}$ & $\begin{array}{c}\text { Haste por } \\
\text { metro }\end{array}$ & $\begin{array}{c}\text { Índice de } \\
\text { clorofila }\end{array}$ & Produção & $\begin{array}{c}\text { Frutos por } \\
\text { planta }\end{array}$ \\
\hline Tupy & $171,4 \mathrm{a}$ & $5,8 \mathrm{~b}$ & $57,8 \mathrm{a}$ & $1.587 \mathrm{a}$ & $822,1 \mathrm{a}$ \\
Xavante & $77,6 \mathrm{~b}$ & $8,3 \mathrm{a}$ & $57,2 \mathrm{a}$ & $1.263 \mathrm{~b}$ & $721,8 \mathrm{~b}$ \\
\hline $2009 / 2010$ & $-(2)$ & - & - & $1.220 \mathrm{c}$ & - \\
$2010 / 2011$ & - & - & - & $1.349 \mathrm{~b}$ & - \\
$2011 / 2012$ & - & - & - & $1.705 \mathrm{a}$ & - \\
\hline CV $(\%)$ & 38,7 & 28,6 & 3,4 & 14,5 & 19,5 \\
\hline
\end{tabular}

${ }^{(1)}$ Médias seguidas de letras iguais, nas colunas, dentro de cada fator, não diferem pelo teste de Tukey, a 5\% de probabilidade. ${ }^{(2)}$ Dados avaliados em apenas uma safra.
A cultivar Tupy apresentou maior concentração foliar de K, Ca, Mg e S do que a Xavante. Como a cultivar Tupy também é mais produtiva e apresenta maior crescimento vegetativo, seu cultivo deve apresentar maior exportação de nutrientes pelos frutos e pelo material retirado na poda. A dose para máxima produtividade foi de $128 \mathrm{e}$ $106 \mathrm{~kg} \mathrm{ha}^{-1} \mathrm{de} \mathrm{N}$, para 'Tupy' e 'Xavante', respectivamente. Em geral, essas doses são superiores às recomendadas na literatura, especialmente no caso da cultivar Tupy. Strik (2008) recomenda de 25 a $45 \mathrm{~kg} \mathrm{ha}^{-1}$ de $\mathrm{N}$ para cultivares de amoreira-preta eretas e semieretas, respectivamente, por ocasião do estabelecimento da cultura; e até $60 \mathrm{~kg} \mathrm{ha}^{-1}$ nos anos seguintes. Em estudos com framboeseira (R. ideaus L.), Quezada et al. (2007) e Gercekcioglu (2008) obtiveram máxima produtividade com doses de 56 e $100 \mathrm{~kg} \mathrm{ha}^{-1} \mathrm{~N}$, respectivamente. As diferenças nas doses ótimas encontradas na literatura e as do presente experimento estão relacionadas às exigências nutricionais de cada genótipo (Strik, 2008) e também aos baixos teores de matéria orgânica $\left(11 \mathrm{~g} \mathrm{~kg}^{-1}\right)$ do solo na área experimental (Manual de adubação e calagem para os estados do Rio Grande do Sul e Santa Catarina, 2004).

Nas safras 2009/2010, 2010/2011 e 2011/2012, as doses para máxima produtividade foram de 16,30, 15,24 e 23,31 g de $\mathrm{N}$ por planta, respectivamente. Comparadas ao tratamento sem adubação, essas doses proporcionaram incrementos de 18,26 e $31 \%$ na produtividade de frutos, nas safras 2009/2010, 2010/2011 e 2011/2012, respectivamente (Figura 1).

A resposta da produção de frutos à adubação nitrogenada foi semelhante à relatada para amoreira-preta por Naraguma \& Clark (1998) e Strik (2008), com incrementos na produtividade até uma dose de máxima, seguido de queda. A queda na produtividade, observada a partir de determinada dose, pode ser explicada pelo desequilíbrio nutricional causado por doses elevadas de $\mathrm{N}$, que tendem a interferir na absorção e assimilação de outros nutrientes (Spiers \& Braswell, 2002; Castaño et al., 2008). $\mathrm{O}$ efeito das doses de $\mathrm{N}$ sobre os teores foliares de $\mathrm{K}$, por exemplo, foi muito pronunciado no presente estudo (Figura 2). O K é considerado um elemento de grande importância para a produção da amoreira-preta (Rincon \& Salas, 1987; Castaño et al., 2008) e, portanto, o desequilíbrio na nutrição com este elemento pode ter grande impacto sobre a produtividade.

A cultivar Tupy produziu mais frutos que a Xavante (Tabela 1). Independentemente da cultivar, houve

Pesq. agropec. bras., Brasília, v.48, n.4, p.373-380, abr. 2013 DOI: 10.1590/S0100-204X2013000400004 
aumento progressivo da produtividade ao longo dos anos, das safras 2009/2010 à 2011/2012 (Figura 1). Este aumento pode ser explicado pelo maior desenvolvimento de órgãos perenes da planta, como sistema radicular e coroa.

Com relação à recomendação atual de adubação nitrogenada, observa-se que há a necessidade de refinamento. Para a cultivar Xavante, a dose recomendada de $100 \mathrm{~kg} \mathrm{ha}^{-1}$ (Manual de adubação e calagem para os estados do Rio Grande do Sul e Santa Catarina, 2004) foi muito similar à estimada no presente trabalho (106 kg ha-1). Porém, para a cultivar Tupy, verifica-se que há necessidade de aumento na dose recomendada. Observa-se, ainda, que a necessidade nutricional da cultura aumenta a partir da terceira safra, possivelmente em razão do aumento da exportação de nutrientes pela produção. Atualmente, fatores como cultivar ou grupos de cultivares não são considerados nas recomendações realizadas no Brasil, tampouco a idade da planta ou a exportação de nutrientes.

Quanto ao teor de N nas folhas, houve interação entre doses, cultivares e safras. Na cultivar Tupy, a concentração de $\mathrm{N}$ na folha aumentou linearmente com as doses aplicadas, nas três safras avaliadas (Figura 2). No entanto, na Xavante, o teor de $\mathrm{N}$ nas folhas teve comportamento quadrático, nas safras 2009/2010 e 2011/2012, e linear em 2010/2011. A resposta diferencial das cultivares à adubação nitrogenada está relacionada à exigência nutricional de cada uma. Segundo Pereira (2008), as cultivares Tupy e Xavante possuem exigências nutricionais distintas, em razão da exportação de nutrientes diferenciada. Assim, os resultados obtidos indicam que, com quantidades elevadas de sulfato de amônio, Xavante apresenta menor eficiência na absorção de $\mathrm{N}$, uma vez que, em duas das três safras avaliadas, a partir de determinada dose, a concentração do elemento tendeu a diminuir em resposta à adubação, sem que tenha havido um incremento desproporcional na produção de matéria seca (Figuras 1 e 2). Uma possível redução do $\mathrm{pH}$ do solo, decorrente da aplicação de doses elevadas de sulfato de amônio (Silva \& Vale, 2000), pode ter causado essa menor eficiência. $\mathrm{O}$ aumento linear na concentração de $\mathrm{N}$ observado para a cultivar Xavante na safra 2010/2011 pode estar associado ao deficit hídrico ocorrido nesse período (Figura 3), que teria

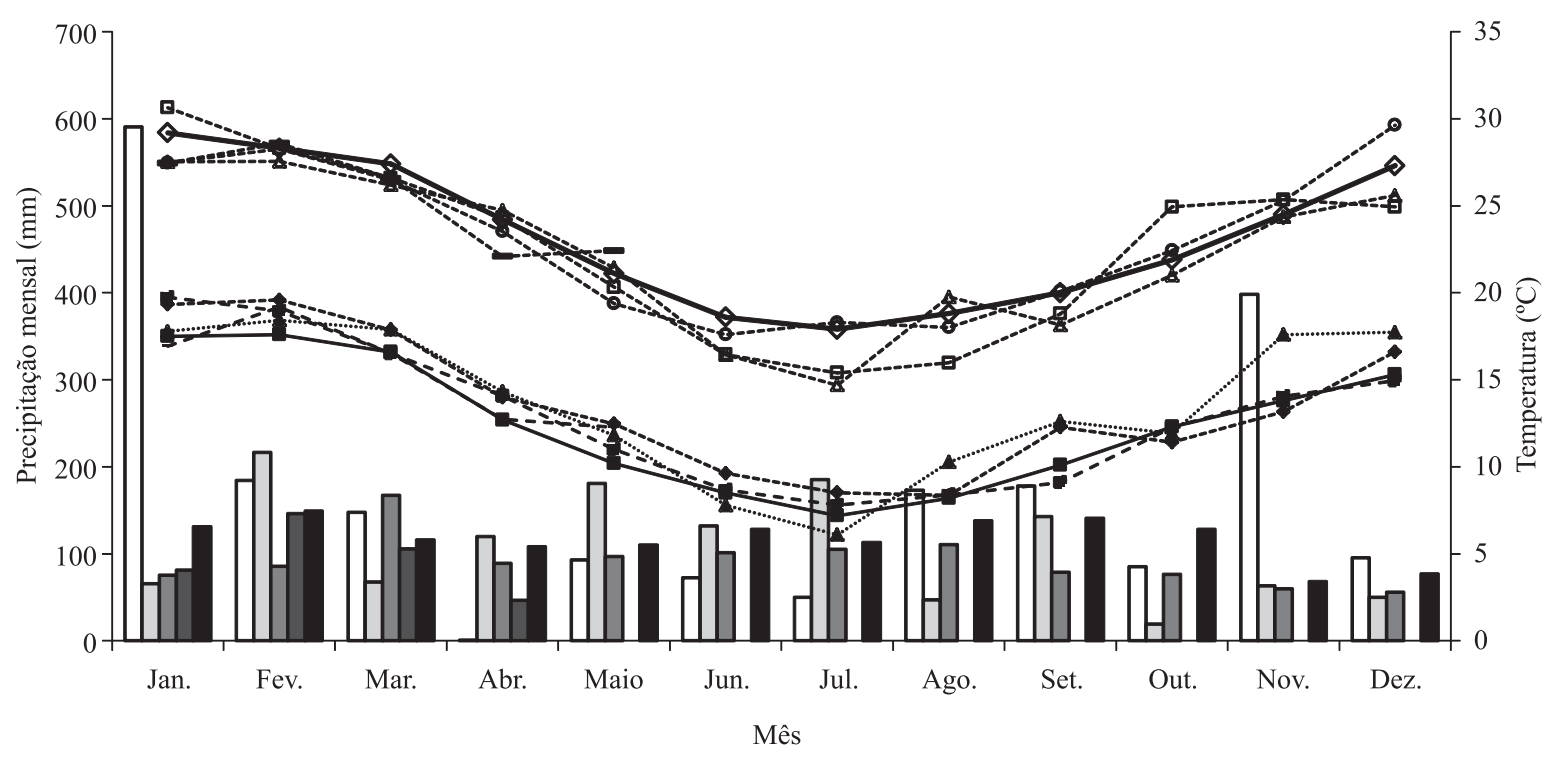

\begin{tabular}{|c|c|c|c|}
\hline$\square$ Precipitação 2009 & $\square$ Precipitação 2010 & $\square$ Precipitação 2011 & Precipitação 2012 \\
\hline ….............. $\mathrm{T}_{\text {Min. }} 2009$ & 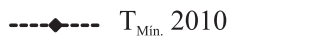 & $----\mathrm{T}_{\text {Min. }} 2011$ & - - - - $\mathrm{T}_{\min } 2012$ \\
\hline ---_---- T T & ----@---- $\quad \mathrm{T}_{\text {Max́ }} 2010$ & ----曰---- T T Máx. 2011 & $\ldots T_{\text {Mах }} 2012$ \\
\hline
\end{tabular}

Figura 3. Temperatura máxima, mínima e precipitação mensal e normal, nos anos 2009, 2010, 2011 e 2012 (até abril), na Estação Meteorológica da Embrapa Clima Temperado, em Pelotas, RS. Fonte: Laboratório de Agrometeorologia da Embrapa Clima Temperado. 
restringido a produção de matéria seca e facilitado o acúmulo do nutriente nas folhas.

A diminuição das concentrações foliares de $\mathrm{K}$ (Figura 2) resultante do aumento nas doses de $\mathrm{N}$ revela uma relação de antagonismo entre esses nutrientes, diferentemente do relatado por Castaño et al. (2008), que observaram correlação positiva significativa entre seus teores na amoreira-preta. Outra explicação para esse resultado refere-se a um possível efeito de diluição, em que o estímulo linear à produção de matéria seca, causado pela adubação nitrogenada (Figura 1), teria dificultado ao acúmulo de $\mathrm{K}$ nas folhas. Este resultado está de acordo com a recomendação de aplicação conjunta desses nutrientes, mencionada por Castaño et al. (2008), em que deve-se buscar uma relação de aplicação de $\mathrm{K} / \mathrm{N}$ de 1,5 . Os teores de $\mathrm{Ca}$, $\mathrm{Mg}$ e $\mathrm{S}$ apresentaram resposta quadrática à adubação nitrogenada (Figura 2).

Os fatores cultivar e safratambém tiveram efeito sobre a concentração foliar de alguns nutrientes (Tabela 2). A cultivar Tupy apresentou maior concentração foliar de $\mathrm{K}, \mathrm{Ca}, \mathrm{Mg}$ e $\mathrm{S}$, e não houve diferença significativa quanto ao teor de N. Quanto às safras, os elementos N e K tiveram os maiores acúmulos na safra 2010/2011, possivelmente, em consequência do deficit hídrico, que induziu o menor crescimento. Nesta mesma safra, verificou-se, também, menor concentração de $\mathrm{Ca}$ e $\mathrm{Mg}$, o que mais uma vez pode estar relacionado ao deficit hídrico, pois, a falta de umidade no solo dificulta o movimento e absorção desses nutrientes. Além disso, o aumento da concentração de K na safra 2010/2011 pode ter contribuído para a menor absorção desses elementos, em razão da relação de competição existente entre eles.

Tabela 2. Concentrações de N, K, Ca, Mg e S, nas folhas das cultivares Tupy e Xavante, e nas safras 2009/2010, 2010/2011 e 2011/2012(1).

\begin{tabular}{lccccc}
\hline Cultivar/safra & $\mathrm{N}$ & $\mathrm{K}$ & $\mathrm{Ca}$ & $\mathrm{Mg}$ & $\mathrm{S}$ \\
& ---------------- \\
\hline Tupy & $25,64 \mathrm{a}$ & $9,89 \mathrm{a}$ & $8,76 \mathrm{a}$ & $3,56 \mathrm{a}$ & $1,12 \mathrm{a}$ \\
Xavante & $25,31 \mathrm{a}$ & $10,70 \mathrm{~b}$ & $6,95 \mathrm{~b}$ & $3,19 \mathrm{~b}$ & $0,93 \mathrm{~b}$ \\
\hline $2009 / 2010$ & $25,65 \mathrm{~b}$ & $9,08 \mathrm{~b}$ & $10,18 \mathrm{a}$ & $3,60 \mathrm{a}$ & $-(2)$ \\
$2010 / 2011$ & $29,24 \mathrm{a}$ & $12,45 \mathrm{a}$ & $6,02 \mathrm{c}$ & $3,13 \mathrm{~b}$ & - \\
$2011 / 2012$ & $21,53 \mathrm{c}$ & $9,35 \mathrm{~b}$ & $7,35 \mathrm{~b}$ & $3,40 \mathrm{a}$ & - \\
\hline $\mathrm{CV}(\%)$ & 6,80 & 8,33 & 15,57 & 13,50 & 9,01 \\
\hline
\end{tabular}

${ }^{(1)}$ Médias seguidas de letras iguais, nas colunas, dentro de cada fator, não diferem pelo teste de Tukey, a 5\% de probabilidade. ${ }^{(2)}$ Dados avaliados em apenas uma safra.

\section{Conclusões}

1. O crescimento vegetativo da amoreira-preta é favorecido de forma linear pela adubação nitrogenada de manutenção.

2. Os genótipos de amoreira-preta respondem de forma diferente à adubação nitrogenada, em que 'Tupy' é mais exigente em $\mathrm{N}$ do que 'Xavante'.

3. A dose de $\mathrm{N}$ recomendada atualmente para a cultura da amoreira-preta é satisfatória para a máxima produção da cultivar Xavante e insuficiente para a da Tupy.

4. A adubação nitrogenada da cultura de amoreirapreta deve ser aumentada, a partir da terceira safra.

\section{Agradecimentos}

À Coordenação de Aperfeiçoamento de Pessoal de Nível Superior (Capes) e ao Conselho Nacional de Desenvolvimento Científico e Tecnológico (CNPq), por apoio financeiro.

\section{Referências}

ALLEYNE, V.; CLARK, J.R. Fruit composition of 'Arapaho' blackberry following nitrogen fertilization. HortScience, v.32, p.282-283,1997.

ANTUNES, L.E.C.; GONÇALVES, E.D.; TREVISAN, R. Fenologia e produção de cultivares de amoreira-preta em sistema agroecológico. Ciência Rural, v.40, p.1929-1933, 2010. DOI: 10.1590/S0103-84782010000900012.

BAÑADOS, M.P.; STRIK, B.C.; BRYLA, D.R.; RIGHETTI, T.L. Response of highbush blueberry to nitrogen fertilizer during field establishment. I: Accumulation and allocation of fertilizer nitrogen and biomass. HortScience, v.47, p.648-655, 2012.

BRYLA, D.R.; STRIK, B.C.; BAÑADOS, M.P.; RIGHETTI, T.L. Response of highbush blueberry to nitrogen fertilizer during field establishment - II. Plant nutrient requirements in relation to nitrogen fertilizer supply. Hortscience, v.47, p.917-926, 2012.

BUSKIENE, L.; USELIS, N. The influence of nitrogen and potassium fertilizers on the growth and yield of raspberries cv. 'Polana'. Agronomy Research, v.6, p.27-35, 2008.

CAMPAGNOLO, M.A.; PIO, R. Produção da amoreira-preta 'Tupy' sob diferentes épocas de poda. Ciência Rural, v.42, p.225-231, 2012. DOI: $10.1590 / \mathrm{S} 0103-84782012005000007$.

CASTAÑO, C.A.; MORALES, C.S.; OBANDO, F.H. Evaluación de las deficiencias nutricionales em el cultivo de la mora (Rubus glaucus) en condiciones controladas para bosque montano bajo. Agronomía, v.16, p.75-88, 2008.

FACHINELLO, J.C.; PASA, M. da S.; SCHMTIZ, J.D.; BETEMPS, D.L. Situação e perspectivas da fruticultura de clima 
temperado no Brasil. Revista Brasileira de Fruticultura, v.33, p.109-120, 2011. DOI: 10.1590/S0100-29452011000500014.

GERCEKCIOGLU, R. Cane characteristics of 'Cola II' red raspberry as affected by application of nitrogen fertilizers and organic manure. Journal of Applied Biological Sciences, v.2, p.81-83, 2008.

ILHA, L.L.H. Produção de amora-preta e framboesa em regiões de clima temperado. Informe Agropecuário, v.33, p.58-68, 2012.

JARA-PEÑA, E.; ANGEL V.M.; PROMETEO, S.G. Contenido de N, P, K y rendimiento de frambuesa roja (Rubus idaeus L.) 'Autumn bliss' orgánico asociada con lupino (Lupinus mutabilis Sweet.). Revista Peruana de Biología, v.9, p.84-93, 2002.

KOWALENKO, C.G.; KEMPLER, C.; BITTMAN, S. Do differences in floricane and primocane growth characteristics of raspberry cultivars influence the recycling of nitrogen in the soil-plant system? Acta Horticulturae, v.777, p.453-457, 2008.

MACHADO, A.A.; CONCEIÇÃO, A.R. Sistema de análise estatística para Windows - WinStat. Versão 2.1. Pelotas: UFPel, 2003.

MANUAL de adubação e calagem para os estados do Rio Grade Sul e Santa Catarina. 10.ed. Porto Alegre: Sociedade Brasileira de Ciência do Solo, 2004. 400p.

MOHADJER, P.; STRIK, B.C.; ZEBARTH, B.J.; RIGHETTI, T.L. Nitrogen uptake, partitioning and remobilization in 'Kotata' blackberry in alternate-year production. Journal of Horticultural Science and Biotechnology, v.76, p.700-708, 2001.

NARAGUMA, J.; CLARK, J.R. Effect of nitrogen fertilization on 'Arapaho' thornless blackberry. Communications in Soil Science and Plant Analysis, v.29, p.2775-2783, 1998. DOI: 10.1080/00103629809370152.
NARAGUMA, J.; CLARK, J.R.; NORMAN, R.J.; MCNEW, R.W. Nitrogen uptake and allocation by field-grown 'Arapaho' thornless blackberry. Journal of Plant Nutrition, v.22, p.753-768, 1999. DOI: $10.1080 / 01904169909365669$.

PEREIRA, I.S. Adubação de pré-plantio no crescimento, produção e qualidade da amoreira-preta (Rubus sp.). 2008. 149p. Dissertação (Mestrado) - Universidade Federal de Pelotas, Pelotas.

QUEZADA, C.; VIDAL, I.; LEMUS, L.; SÁNCHEZ, H. Effect of nitrogen fertilization on yield and fruit quality of raspberries (Rubus idaeus L.) under two fertigation programs. Revista de la Ciencia del Suelo y Nutrición Vegetal, v.7, p.1-15, 2007. DOI: 10.4067/S0718-27912007000300001.

RINCON, T.A.R.; SALAS, M.J.A. Influence of the levels of N, $\mathrm{P}$, and K on the yield of blackberry. Acta Horticulturae, v.199, p.183-186, 1987.

SANTOS, H.G. dos; JACOMINE, P.K.T.; ANJOS, L.H.C. dos; OLIVEIRA, V.A. de; OLIVEIRA, J.B. de; COELHO, M.R.; LUMBRERAS, J.F.; CUNHA, T.J.F. (Ed.). Sistema brasileiro de classificação de solos. 2.ed. Rio de janeiro: Embrapa Solos, 2006. $306 \mathrm{p}$.

SILVA, C.A.; VALE, F.R. do. Disponibilidade de nitrato em solos brasileiros sob efeito da calagem e de fontes e doses de nitrogênio. Pesquisa Agropecuária Brasileira, v.35, p.2461-2471, 2000. DOI: $10.1590 /$ S0100-204X2000001200017.

SPIERS, J.M.; BRASWELL, J.H. Influence of N, P, K, Ca, and Mg rates on leaf macronutrient concentration of 'Navaho' blackberry. Acta Horticulturae, v.585, p.659-663, 2002.

STRIK, B.C. A review of nitrogen nutrition of Rubus. Acta Horticulturae, v.777, p.403-410, 2008.

STRIK, B.C.; FINN, C.E. Blackberry production systems - a worldwide perspective. Acta Horticulturae, v.946, p.341-347, 2012.

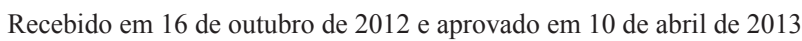

Pesq. agropec. bras., Brasília, v.48, n.4, p.373-380, abr. 2013 